\title{
The structure of phosphate glass evidenced by small angle X-ray scattering
}

\author{
G. Walter $^{\mathrm{a}, *}$, G. Goerigk ${ }^{\mathrm{b}}$, C. Rüssel ${ }^{\mathrm{c}}$ \\ a Institute of Physics, Rostock University, Universitätsplatz 3, Rostock D-18051, Germany \\ ${ }^{\mathrm{b}}$ Institute of Solid State Research, Jülich Research Centre, P.O. Box 1913, Jülich D-52425, Germany \\ c Otto Schott Institute, Friedrich Schiller University Jena, Fraunhoferstraße 6, Jena D-07743, Germany
}

Received 10 April 2006; received in revised form 24 July 2006

\begin{abstract}
Numerous phosphate glass systems with compositions covering the entire glass forming range have been examined by small angle X-

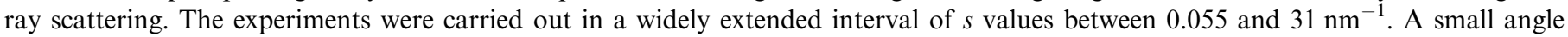
scattering effect was detected for all samples investigated with the exception of the aluminium metaphosphate glass. The small angle scattering recorded indicates the presence of two differently-sized heterogeneity regions of electron density. The small-scale heterogeneities are present in magnesium and zinc phosphate glasses only. Their size is about $1 \mathrm{~nm}$ diameter in the magnesium and about $2 \mathrm{~nm}$ in the zinc phosphate glasses. The species do not result from liquid-liquid phase separation. Examinations to extract information on the nature of these heterogeneity regions are described in detail. There is no fundamental knowledge on the large-scale heterogeneities established. The small angle scattering suggests that their occurrence is related to water contamination. Anomalous small angle X-ray scattering experiments of a series of zinc polyphosphate glasses and a strontium metaphosphate glass sample are performed to examine the distribution of the $\mathrm{Zn}$ or $\mathrm{Sr}$ atoms, respectively.
\end{abstract}

(c) 2006 Elsevier B.V. All rights reserved.

PACS: 61.10.Eq; 61.43.Fs

Keywords: Synchrotron radiation; X-ray diffraction; Phosphates; Submicroscopic structure

\section{Introduction}

A variety of specialty applications of phosphate glasses has been stimulated by some properties and crystallization behavior that are unique to these glasses [1]. From this, the interest in phosphate glasses has been considerably increased in the last two decades. Many efforts have been successfully made to extend and improve the knowledge on the structure of phosphate glasses by different methods like solid state nuclear magnetic resonance (NMR), X-ray and neutron diffraction, high-performance liquid chromatography or X-ray photoelectron, IR and Raman spectros-

\footnotetext{
* Corresponding author. Tel.: +49 381498 6903; fax: +49 3814986862. E-mail address: guenter.walter@physik.uni-rostock.de (G. Walter).
}

copy. In addition, the interpretation of the experimental data has been supported by structural simulations applying reverse Monte Carlo or molecular dynamics techniques. In Brow's 2000 review [2], the progress in phosphate glass science that has been made since 1991 was summarized.

The basic structural unit of all phosphates, crystalline and amorphous, is the $\mathrm{PO}_{4}$ tetrahedron that links with neighboring tetrahedra through covalent bridging oxygen $\left(\mathrm{O}_{\mathrm{B}}\right)$ atoms to form a network. Thus, a range of structures can be made depending on the $[\mathrm{O}] /[\mathrm{P}]$ ratio as set by glass composition. In vitreous phosphorus pentoxide $\left(\mathrm{v}-\mathrm{P}_{2} \mathrm{O}_{5}\right)$ the $\mathrm{PO}_{4}$ tetrahedra are threefold-linked by $\mathrm{O}_{\mathrm{B}}$ atoms whereas one, the terminal oxygen $\left(\mathrm{O}_{\mathrm{T}}\right)$ atom, is doublebonded with the $\mathrm{P}$ atom. The $\mathrm{PO}_{4}$ unit in this structure is referred to as the $\mathrm{Q}^{3}$ group. (The exponent in $\mathrm{Q}^{n}$ denotes 
the number of $\mathrm{O}_{\mathrm{B}}$ atoms in a $\mathrm{PO}_{4}$ unit.) Incorporating a metal oxide into the $\mathrm{PO}_{4}$ network depolymerizes the network structure by converting $\mathrm{O}_{\mathrm{B}}$ atoms to non-bridging oxygen $\left(\mathrm{O}_{\mathrm{NB}}\right)$ atoms by breaking the $\mathrm{P}-\mathrm{O}-\mathrm{P}$ links, which produces $\mathrm{Q}^{2}$ groups. In the ultraphosphate region both units $\mathrm{Q}^{3}$ and $\mathrm{Q}^{2}$ are present in the glass network, whereas in polyphosphate glasses there are no $\mathrm{Q}^{3}$ units. At metaphosphate composition with $[\mathrm{O}] /[\mathrm{P}]=3$, the structure is constituted of infinitely long chains and/or rings formed by $\mathrm{Q}^{2}$ units. With increasing metal oxide content, the average chain length becomes progressively shorter. The structure of polyphosphate glasses with $[\mathrm{O}] /[\mathrm{P}]>3$ is based on $\mathrm{Q}^{2}$ chains terminated by $\mathrm{Q}^{1}$ units. At pyrophosphate stoichiometry $([\mathrm{O}] /[\mathrm{P}]=3.5)$, phosphate dimers, two $\mathrm{Q}^{1}$ tetrahedra linked by a $\mathrm{O}_{\mathrm{B}}$, dominate the structure. Finally, isolated orthophosphate units $\left(\mathrm{Q}^{0}\right.$ groups) are present in glasses for which $[\mathrm{O}] /[\mathrm{P}]=4$.

A great deal of new information on the short and intermediate range structure of phosphate glasses has been extracted by means of diffraction methods. The more recent diffraction studies of phosphate glasses, particularly those published since 1990, were reviewed by Hoppe et al. [3]. The investigations have been directed to the shortrange order $(\sim 0.15-0.3 \mathrm{~nm})$ by using wide angle scattering with X-rays and neutrons, that permits coordination numbers and next neighbor distances of atoms to be determined. Information on the next higher level of structural organization beyond the short-range order, the so-called intermediate range order $(\sim 0.3-1 \mathrm{~nm})$, has been obtained from the X-ray and neutron scattering total structure factor, $S(s)$, at intermediate and small magnitudes of the scattering vector, $s$, where $s=(4 \pi / \lambda) \sin (\theta / 2) ; \theta$ is the scattering angle and $\lambda$ is the X-ray wavelength.

By small angle scattering experiments fluctuations of electron density extending over regions of colloidal dimensions in the glass sample, i.e., $\sim 1-100 \mathrm{~nm}$, can be quantitatively characterized. In the past little interest has been directed to small angle scattering of phosphate glasses. Possibly, this is due to the fact that phase separation is unknown in pure phosphate glasses. Thus, only a small number of publications devoted to investigating phosphate glasses by small angle scattering have appeared. For the first time, small angle $\mathrm{X}$-ray scattering experiments on metaphosphate glasses were reported in 1990 [4] which have shown that small heterogeneities of electron density of about $1 \mathrm{~nm}$ size are present in magnesium metaphosphate glass. More recently, the presence of such heterogeneities was established in a zinc polyphosphate and a sodium-zinc pyrophosphate glass by small angle X-ray scattering [5] and in magnesium [6] and zinc polyphosphate glasses [7] with varying composition. Moreover, a pronounced scattering at smallest $s$ values was reported to be measured with X-rays for zinc phosphate glasses [7] and with neutrons for iron phosphate glass [8].

In this paper, the experimental facts that we have gleaned by small angle X-ray scattering of various phosphate glass systems since 1990 are summarized. New results extracted by extending the measuring range up to appreciably smaller $s$ values are presented. For these experiments the ASAXS-Beamline Jusifa at Hamburg Synchrotron Radiation Laboratory, Germany, was used, that permits the anomalous small angle scattering (ASAXS) to be measured as well.

\section{Method}

\subsection{Small angle $X$-ray scattering}

The term small angle X-ray scattering is reserved for the elastic component of the scattered intensity observed at small $s$ values in the interval $0<s<\pi / d_{\mathrm{A}}$, where $d_{\mathrm{A}}$ denotes the size of the interatomic distances in the sample. The electron density fluctuations within a particle may be differentiated into those of colloidal dimensions, thus being resolved by the small angle X-ray scattering experiment, and into those unresolved fluctuations lying on an atomic scale. As an intuitive example, Fig. 1 presents the experimental scattering curve, $I(s)$, for a zinc metaphosphate

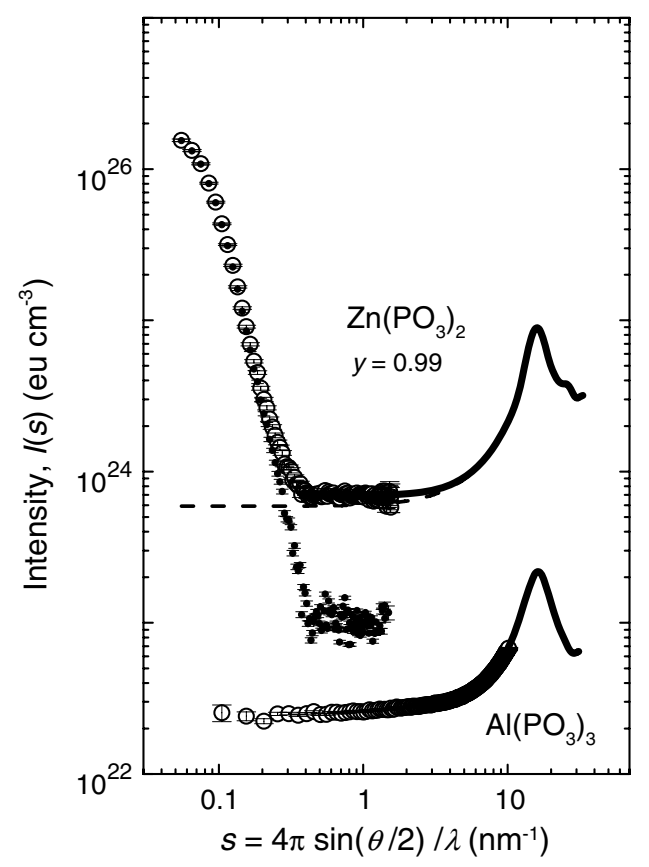

Fig. 1. The X-ray scattering intensities, $I(s)$, for the zinc metaphosphate glass sample with molar ratio $y=0.99$ measured at the ASAXS-Beamline Jusifa far from the $\mathrm{Zn} K$-absorption edge (open circles) and obtained with the Rigaku Denki low angle X-ray goniometer (solid line). The dashed line results from the approximation of the solid lined $I(s)$ curve by a polynomial in $s^{2}$ according to (2). The full circles represent the small angle X-ray scattering after subtracting the approximated curve (dashed line) from the measured intensities (open circles). For comparison, the Xray scattering for the aluminium metaphosphate glass is shown. The open circles of the latter curve indicate the intensities recorded at the ASAXSBeamline Jusifa and the solid lined curve was obtained with the Rigaku Denki low angle X-ray goniometer. For better visibility, the curves of the aluminium metaphosphate glass have been divided by 30 . The uncertainties in $I(s)$ are represented by the error bars or they are within the line widths, respectively (for details see Section 3.2). 
glass containing differently-sized heterogeneity regions. It is obvious that the particle scattering, $I_{\mathrm{P}}(s)$, is distinctly contrasted with the scattering, $I_{\mathrm{F}}(s)$, produced by electron density fluctuations inherent in any glass as a result of the disordered network structure, i.e., local differences in chemical composition and/or the topological density. For comparison, the X-ray scattering for the aluminium metaphosphate glass is shown. This curve does not show an increase of intensity as $s \rightarrow 0$ and is caused only by frozen-in fluctuations of electron density, $I_{\mathrm{F}}(s)$.

The total scattered intensity, $I(s)$, of the glass sample is the result of the interaction of the incident X-rays with any electron density heterogeneities that are met by the beam along its path. If the contributions of interparticle interferences are described by $I_{\mathrm{IP}}(s)$, the intensity function, $I(s)$, can be expressed in a good approximation by [9]

$I(s)=I_{\mathrm{P}}(s)+I_{\mathrm{IP}}(s)+I_{\mathrm{F}}(s)$.

In the majority of structural investigations, the interest is exclusively focused on the analysis of the particle scattering, $I_{\mathrm{P}}(s)$. In this case, the contributions $I_{\mathrm{F}}(s)$, and possibly $I_{\mathrm{IP}}(s)$, must be mathematically eliminated in a previous step.

For this purpose, the scattering of the disordered network, $I_{\mathrm{F}}(s)$, can be approximated by the polynomial [10]

$I_{\mathrm{F}}(s)=\sum_{i=0}^{j} \frac{I_{i}}{i !} s^{2 i}$

where the $I_{i}$ are constant. In Fig. 1, the dashed line results from the approximation of the solid lined $I(s)$ curve in the interval $5 \leqslant s \leqslant 6.8 \mathrm{~nm}^{-1}$ by using (2). The zero-angle scattering, $I_{\mathrm{F}}(0)$, is a measure of the magnitude of the electron density fluctuations in the glass [11].

The term $I_{\mathrm{P}}(s)$ in (1) is not restricted to systems containing well defined particles but can be applied to heterogeneities of electron density of any kind possessing colloidal dimensions, e.g., non-particulate interconnected structures such as observed as a result of spinodal decomposition [12] or in porous glasses [13]. If the intensity, $I_{\mathrm{P}}(s)$, originates from globular particles, the Guinier approximation [14]

$I_{\mathrm{P}}(s)=I_{\mathrm{P}}(0) \exp \left(-s^{2} \frac{R_{\mathrm{g}}^{2}}{3}\right)$

can be applied to determine the radius of gyration, $R_{\mathrm{g}}$. Then, the radius of spherical particles, $R$, is given by the relation

$R_{\mathrm{g}}=\sqrt{\frac{3}{5}} R$

To obtain reliable results by applying (3), scattered intensities have to be measured in a range [15]

$s_{\min } \leqslant s \lesssim 1.26 / R$,

with $R$ expressed in $\mathrm{nm}$, and $s_{\min }$ stands for the smallest $s$ value measured. The number, $N$, of particles with radius, $R$, can be estimated using the formula
$N=\frac{3 w_{\mathrm{P}}}{4 \pi R^{3}}$.

The volume fractions of the particles, $w_{\mathrm{P}}$, and the matrix phase, $\left(1-w_{\mathrm{P}}\right)$, can be extracted from the mean-square electron density fluctuations, $\overline{(\Delta \rho)^{2}}$, that are related to the second moment of the intensity function, $I_{\mathrm{P}}(s)$, expressed by [16]

$\overline{(\Delta \rho)^{2}}=w_{\mathrm{P}}\left(1-w_{\mathrm{P}}\right)(\Delta \rho)^{2}=\frac{1}{2 \pi^{2}} \int_{0}^{\infty} s^{2} I_{\mathrm{P}}(s) \mathrm{d} s$.

In (7), $\Delta \rho=\left|\rho_{\mathrm{P}}-\rho_{\mathrm{M}}\right|$ represents the 'excess electron density' or 'contrast' between particle (P) and matrix (M).

\subsection{Anomalous small angle $X$-ray scattering}

Anomalous small angle X-ray scattering techniques provide the possibility of contrast variation by measuring the scattering intensities at different energies. Thus, information can be extracted on the spatial distribution of certain elements within the sample.

The scattered intensity of homogeneous particles with identical size distributed in a homogeneous matrix phase measured in absolute units can be written as [16]

$I(s, E)=w_{\mathrm{P}}\left(1-w_{\mathrm{P}}\right) V\left|\rho_{\mathrm{P}}(E)-\rho_{\mathrm{M}}(E)\right|^{2} \Phi(s)$.

$V$ stands for the volume of the particles and $\Phi(s)$ is their form factor and is normalized so that $\Phi(0)=1$. The contrast, $\Delta \rho$, is determined by the X-ray energy, $E$, expressed by [17]

$\Delta \rho(r, E)=\Delta \rho_{0}(r)+\left[f^{\prime}(E)+\mathrm{i} f^{\prime \prime}(E)\right] \Delta \rho_{\mathrm{a}}^{\prime}(r)$,

where $\Delta \rho_{0}(r)$ is the contrast far away from the resonance. The alteration of $\Delta \rho(r)$ with changing X-ray energy towards the absorption edge is given by the second term in (9). $\left(\Delta \rho_{\mathrm{a}}^{\prime}(r)\right.$ describes the positions of the anomalous scatters; $f^{\prime}$ and $f^{\prime \prime}$ are the anomalous corrections.) By using (8), the comparison of the scattered intensities measured far from and close to the absorption edge qualitatively permits conclusions to be drawn on the concentration of the resonant scattering atoms within the particle phase with respect to that of the matrix. (The shape of $\Phi(s)$ remains unchanged if the resonant scattering atoms are homogenously distributed within the particles.)

\section{Experimental}

\subsection{Glass preparation and characterization}

The analyzed compositions and melting characteristics of the metaphosphate glasses included in this study are listed in Table 1. The glasses were melted from sintered metaphosphates in silica crucible in air. The liquids were poured onto a cold block of copper and subsequently the glasses were shattered and remelted in a platinum crucible for $15 \mathrm{~min}$ at the temperatures given in Table 1. After casting into closed blocks of copper the liquids were annealed 
Table 1

Compositions, densities and melting characteristics for the metaphosphate glasses examined in this study

\begin{tabular}{|c|c|c|c|c|c|c|}
\hline \multirow[t]{2}{*}{ Glass } & \multicolumn{2}{|c|}{ Mol\% by analysis } & \multirow[t]{2}{*}{ Density $\left(\mathrm{g} / \mathrm{cm}^{3}\right)$} & \multirow[t]{2}{*}{ Melting temperature $(\mathrm{K})$} & \multirow[t]{2}{*}{ Time $(\min )$} & \multirow[t]{2}{*}{ Annealing Initial temperature $(\mathrm{K})$} \\
\hline & Metal oxide & $\mathrm{P}_{2} \mathrm{O}_{5}$ & & & & \\
\hline $\mathrm{NaPO}_{3}$ & 49.4 & 50.6 & 2.491 & 850 & 25 & 325 \\
\hline $\mathrm{Mg}\left(\mathrm{PO}_{3}\right)_{2}$ & 48.9 & 51.1 & 2.415 & 1400 & 15 & 500 \\
\hline $\mathrm{Ca}\left(\mathrm{PO}_{3}\right)_{2}$ & 48.3 & 51.7 & 2.642 & 1300 & 15 & 500 \\
\hline $\mathrm{Sr}\left(\mathrm{PO}_{3}\right)_{2}$ & 50.4 & 49.6 & 3.158 & 1300 & 15 & 500 \\
\hline $\mathrm{Al}\left(\mathrm{PO}_{3}\right)_{3}$ & $25.4^{\mathrm{a}}$ & $73.6^{\mathrm{a}}$ & 2.612 & 1920 & 30 & 855 \\
\hline
\end{tabular}

a $1.0 \mathrm{~mol}^{\%} \mathrm{SiO}_{2}$ due to corrosion of the crucible was analyzed.

to room temperature. To determine their exact composition, the glasses were analyzed after the heat treatment by energy-dispersive X-ray analysis using a scanning electron microscope. The aluminium phosphate glass sample was taken from our earlier investigations of its short and intermediate range structure described in Refs. [18,19], respectively.

A series of zinc polyphosphate glasses from metaphosphate towards orthophosphate composition was prepared (Table 2). The raw materials used were analytical grade zinc carbonate and zinc metaphosphate. Stoichiometric mixtures were melted in silica crucibles in air at $1300{ }^{\circ} \mathrm{C}$ for $0.5 \mathrm{~h}$. The liquids were poured onto copper blocks and subsequently the glasses were shattered and remelted in a platinum crucible at $1300{ }^{\circ} \mathrm{C}$ for $0.5 \mathrm{~h}$ in order to improve their homogeneity. After casting into coppermoulds the liquids were annealed to room temperature from an initial temperature of $450{ }^{\circ} \mathrm{C}$ (rate: $5 \mathrm{~K} / \mathrm{min}$ ). Melts containing more than $60 \mathrm{~mol} \% \mathrm{ZnO}$ were quenched between the copper block and a copper plate to prevent crystallization. The contents of phosphorus and zinc of each sample were analyzed by means of the electron microprobe. $\mathrm{SiO}_{2}$ that could be incorporated into the glasses due to some attack of the crucible was not detectable. Note that less than about $0.5 \mathrm{~mol} \% \mathrm{SiO}_{2}$ cannot be detected by the technique used. The results of the analyses are listed in Table 2.

The magnesium phosphate glasses discussed in this report are listed in Table 3. (The glass with molar ratio $y=0.96$ is identical with the $\mathrm{Mg}\left(\mathrm{PO}_{3}\right)_{2}$ sample listed in Table 1.) Preparation procedures are detailed described in Ref. [6] (sample with $y=1.49$ ) and in Ref. [20] (samples with $y=0.87$ and 1.13 ) where also properties and struc-

Table 2

Compositions and densities for the $\mathrm{ZnO}-\mathrm{P}_{2} \mathrm{O}_{5}$ glasses examined in this study

\begin{tabular}{llll}
\hline$y$ & \multicolumn{2}{l}{$\mathrm{Mol} \%$ by analysis } & Density $\left(\mathrm{g} / \mathrm{cm}^{3}\right)$ \\
\cline { 2 - 3 } & $\mathrm{ZnO}$ & $\mathrm{P}_{2} \mathrm{O}_{5}$ & \\
\hline 0.99 & 49.7 & 50.3 & 2.846 \\
1.17 & 53.9 & 46.1 & 2.977 \\
1.81 & 64.4 & 35.6 & 3.444 \\
2.27 & 69.4 & 30.6 & 3.765 \\
\hline
\end{tabular}

$y$ denotes the zinc oxide to phosphorus pentoxide ratio.
Table 3

Compositions and densities for the $\mathrm{MgO}-\mathrm{P}_{2} \mathrm{O}_{5}$ glasses examined in this study

\begin{tabular}{llll}
\hline$y$ & \multicolumn{2}{l}{$\mathrm{Mol} \%$ by analysis } & Density $\left(\mathrm{g} / \mathrm{cm}^{3}\right)$ \\
\cline { 2 - 3 } & $\mathrm{MgO}$ & $\mathrm{P}_{2} \mathrm{O}_{5}$ & \\
\hline 0.87 & 46.6 & 53.4 & 2.462 \\
0.96 & 48.9 & 51.1 & 2.415 \\
1.13 & 53.0 & 47.0 & 2.442 \\
1.49 & 58.9 & 39.6 & 2.650 \\
\hline
\end{tabular}

The remaining fraction exceeding the totalized content of $\mathrm{MgO}$ and $\mathrm{P}_{2} \mathrm{O}_{5}$ is $\mathrm{SiO}_{2}$ due to corrosion of the crucible. $y$ denotes the magnesium oxide to phosphorus pentoxide ratio.

tural analyzes of the short and intermediate range structure are presented.

In Tables 1-3, the estimated uncertainty of the analyzed compositions is about $\pm 1 \mathrm{~mol} \%$. Mass density was measured by the Archimedes method using benzene. The relative precision of the measured densities was $\pm 0.2 \%$.

The molar ratios, $y=n(\mathrm{MeO}) / n\left(\mathrm{P}_{2} \mathrm{O}_{5}\right)$, with $\mathrm{Me}=\mathrm{Zn}$ or $\mathrm{Mg}$, will be used when considering the compositiondependence of quantitative relationships.

For the X-ray scattering measurements slab-shaped samples were prepared with a thickness of $\sim 1 / \mu$, where $\mu$ is the linear absorption coefficient for the X-rays used. The samples were polished on both sides.

\subsection{Structural analysis}

The small angle X-ray scattering of the samples was measured with pinhole collimation at ASAXS-Beamline Jusifa at Hamburg Synchrotron Radiation Laboratory, Germany.

The experiments for studying the series of metaphosphate glasses shown in Fig. 2 were performed at photon energy of $15610 \mathrm{eV}(\lambda=0.0795 \mathrm{~nm})$, far from the $K$-absorption edge of $\mathrm{Sr}(16105 \mathrm{eV})$. Two values of sample-detector distance were employed $(935 \mathrm{~mm}$ and $3635 \mathrm{~mm}$, respectively) in order to cover a wide range of scattering angles. The two curves for a given sample were joined in the regions were they overlapped. From this, the scattering curves, $I(s)$, were obtained in the interval $0.105 \leqslant s \leqslant 10.175 \mathrm{~nm}^{-1}$. The $\mathrm{Sr}$ phosphate glass, and for comparison the Al metaphosphate glass sample, were also investigated at energy $16051 \mathrm{eV}(\lambda=0.0773 \mathrm{~nm})$, i.e., $54 \mathrm{eV}$ below the $K$-absorp- 


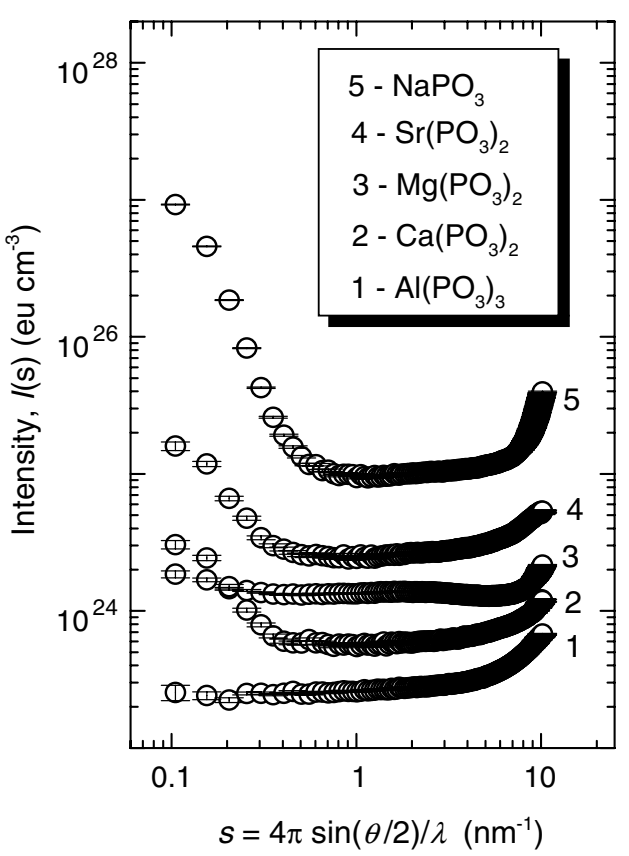

Fig. 2. The small angle X-ray scattering intensities, $I(s)$, for a series of metaphosphate glass samples indicated in the plot. The curves were measured at the ASAXS-Beamline Jusifa at Hamburg Synchrotron Radiation Laboratory. For better visibility, the curve of the sodium phosphate glass has been multiplied by 30 , that of strontium phosphate glass by 3 , and the curve of the aluminium phosphate glass has been divided by 3 . The uncertainties in $I(s)$ are represented by the error bars.

tion edge of Sr. This energy was chosen to avoid contributions of resonant X-ray Raman scattering (for further details see Section 5.4) as far as possible. Because of the relatively high concentration of $\mathrm{Sr}$ atoms in the sample $(50.4 \mathrm{~mol} \% \mathrm{SrO})$ a dominant contribution of resonant Raman scattering is observed in relation to the weak small angle scattering signal in the near neighborhood of the $K$ absorption edge. The onset of the resonant Raman scattering becomes already noticeable $54 \mathrm{eV}$ below the edge as can be seen from Fig. 7.

The polyphosphate glasses of compositions $\mathrm{ZnO}-\mathrm{P}_{2} \mathrm{O}_{5}$, with $y=0.99$ up to 2.27 (Fig. 3) and $\mathrm{MgO}-\mathrm{P}_{2} \mathrm{O}_{5}$, with $y=1.49$, (Fig. 5) were measured at beam energy of $9330 \mathrm{eV}(\lambda=0.133 \mathrm{~nm})$, far from the $K$-absorption edge of $\mathrm{Zn}(9659 \mathrm{eV})$. The series of $\mathrm{Zn}$ phosphate glass samples was also investigated at energy of $9617 \mathrm{eV}(\lambda=0.129 \mathrm{~nm})$, close to the $\mathrm{Zn} K$-absorption edge. The intensity functions, $I(s)$, were recorded for $0.055 \leqslant s \leqslant 1.595 \mathrm{~nm}^{-1}$. The $\mathrm{MgO}-$ $\mathrm{P}_{2} \mathrm{O}_{5}$ glass samples with $y=0.87$ and 1.13 (Fig. 5) were measured at photon energy of $11232 \mathrm{eV}(\lambda=0.11 \mathrm{~nm})$ for $0.109 \leqslant s \leqslant 7.8 \mathrm{~nm}^{-1}$.

The ASAXS data were processed using the software available at the beamline, which covers integrations, corrections for transmission and detector sensitivity, subtraction of background and dark current, and combination of the scattering curves recorded at different sample-detector distances. The scattering curves were calibrated into absolute units of cross-section per unit volume $\left(\mathrm{eu} / \mathrm{cm}^{3}\right)$.

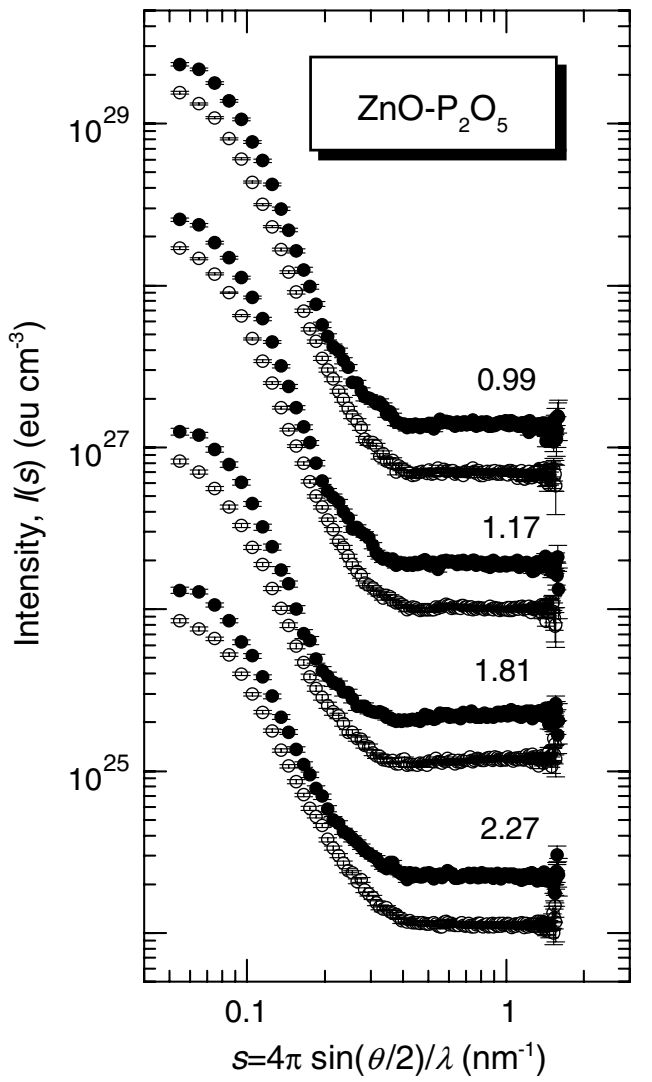

Fig. 3. The anomalous small angle $\mathrm{X}$-ray scattering of zinc polyphosphate glasses with molar ratios, $y$, indicated in the plot. The curves were recorded far from the $\mathrm{Zn} K$-absorption edge (open circles, $9330 \mathrm{eV}$ ) and close to the edge (full circles, $9617 \mathrm{eV}$ ). For better visibility, the two curves for $y=1.81$ have been multiplied by 10 , those for $y=1.17$ by $10^{2}$ and the curves for $y=0.99$ by $10^{3}$. The uncertainties in $I(s)$ are represented by the error bars.

The X-ray scattering at intermediate $s$ values was measured with a low angle X-ray goniometer (Rigaku Denki) using $\mathrm{AgK}_{\alpha}$ or $\mathrm{MoK}_{\alpha}$ radiation, respectively. The intensities were recorded in the range between $s_{1}=0.4 \mathrm{~nm}^{-1}$ and $s_{2}=38 \mathrm{~nm}^{-1}$ for $\operatorname{AgK}_{\alpha}$ and between $s_{1}=0.3 \mathrm{~nm}^{-1}$ and $s_{2}=31 \mathrm{~nm}^{-1}$ for $\operatorname{MoK}_{\alpha}$. The $\theta$ increment for the measurements was $0.1^{\circ}$. Being distorted by the length of the cross-section of the primary beam the scattering curves were corrected for collimation effects by the method given in Ref. [21] as the result of which continuous curves were provided from analytical expressions. This technique includes a frequency-filtering procedure, where a smoothed scattering curve is generated. The residual statistical noise is within the line width of the scattering curves shown in Figs. 1 and 5. All procedures used for data collection and corrections of the recorded intensities are described in [11].

\section{Results}

The small angle X-ray scattering, $I(s)$, of the metaphosphate glasses (Table 1) is shown in Fig. 2. The intensities have been converted into absolute units (electron units; eu). Each sample was prepared and measured under equal 
circumstances. Having been prepared the glasses were kept in sealed evacuated ampoules to protect them against moisture attack. (Note that the aluminium phosphate glass sample was prepared several years ago as mentioned above.) All fife samples were brought into the vacuum chamber of the small angle X-ray scattering device at once, mounted on one sample holder.

The small angle X-ray scattering for the series of zinc polyphosphate glasses (Table 2) including a glass of metaphosphate composition $(y=0.99)$ is shown in Fig. 3. The scattering was measured far from $(9330 \mathrm{eV})$ and close to $(9617 \mathrm{eV})$ the $K$-absorption edge of $\mathrm{Zn}$ at $9659 \mathrm{eV}$. This approach represents one of the techniques of anomalous small angle $\mathrm{X}$-ray scattering that provides the possibility of changing the excess electron density of a particle or its components.

In Fig. 4, the X-ray scattering intensities for the zinc polyphosphate glasses measured far from the absorption edge (open circles in Fig. 3) are drawn in a Guinier plot according to Eq. (3), i.e., the logarithm of the intensity is plotted versus $s^{2}$. The scattering of the disordered network, $I_{\mathrm{F}}(s)$, has been removed in each curve as demonstrated in Fig. 1. The curves in Fig. 4 indicate the presence of two differently-sized heterogeneities of electron density in the samples. According to (3) and (4), from the slope of the straight lines in Fig. 4 the radius of sphere, $R$, of the small-scale heterogeneities was obtained to be about $1 \mathrm{~nm}$ for the glasses with the molar ratios $y=0.99,1.17$ and 2.27.

Fig. 5 shows the X-ray scattering curves for magnesium phosphate glasses which were selected from a series of samples. In Refs. [6,20], the short and intermediate range structure of these glasses was investigated. Thus the samples discussed in this study are differently old, but basically all samples have been stored under vacuum to reduce the water incorporation. The small angle X-ray scattering intensities recorded at the ASAXS-Beamline Jusifa were joined in the regions where they overlap with the curves obtained with the Rigaku Denki low angle X-ray goniometer. For the sample with $y=0.87$, the scattering measured

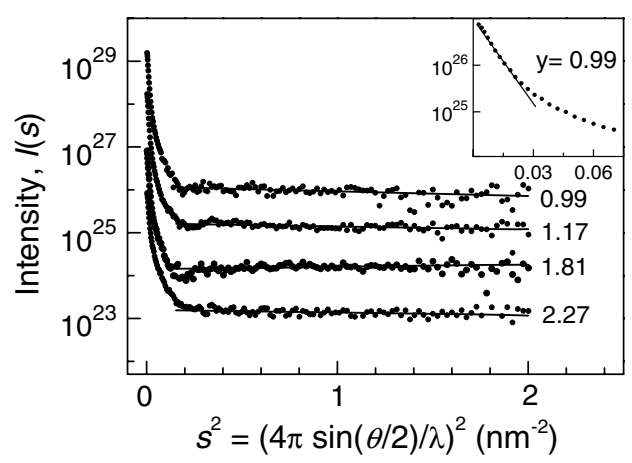

Fig. 4. Guinier plot of the experimental small angle X-ray scattering curves of the zinc polyphosphate glasses shown in Fig. 3 by the open circles, with fitted lines. The scattering of the disordered network has been removed as demonstrated in Fig. 1. The inset is the enlargement of the scattering curve for the metaphosphate glass $(y=0.99)$ in the interval $s_{\min } \leqslant s \leqslant 0.07 \mathrm{~nm}^{-1}$.

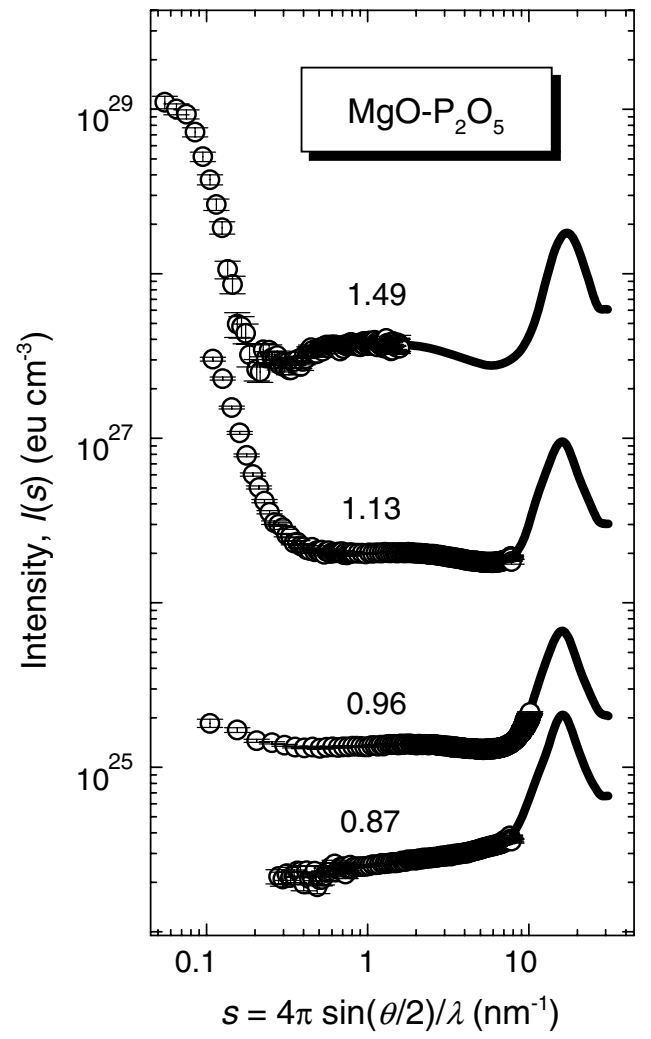

Fig. 5. The X-ray scattering curves, $I(s)$, for the magnesium phosphate glass samples measured at the ASAXS-Beamline Jusifa (open circles) and obtained with the Rigaku Denki low angle X-ray goniometer (solid lines). The magnesium oxide to phosphorus pentoxide molar ratios, $y$, are indicated in the plot. For better visibility, the curve for $y=0.96$ has been multiplied by 10 , that for $y=1.13$ by $10^{2}$ and the curve for $y=1.49$ by $10^{3}$. The uncertainties in $I(s)$ are represented by the error bars or they are within the line widths, respectively (for details see Section 3.2).

for $s \lesssim 0.28 \mathrm{~nm}^{-1}$ was such poor in intensity that reliable values in this $s$ range could not be obtained after making corrections.

The particle scattering curves, $I_{\mathrm{P}}(s)$, for the magnesium phosphate glasses were extracted by separating the scattering $I_{\mathrm{F}}(s)$ from the intensity functions shown in Fig. 5 as demonstrated for the zinc metaphosphate glass (cf. Fig. 1). The size of the heterogeneities was determined from a Guinier plot of the scattering curves $I_{\mathrm{P}}(s)$. Using the Eqs. (3) and (4) $R \sim 0.5 \mathrm{~nm}$ was obtained for the samples with $y=0.96,1.13$ and 1.49 .

In Fig. 6, the dependence of the mean-square electron density fluctuations, $\overline{(\Delta \rho)^{2}}$, on composition is shown. The values, $\overline{(\Delta \rho)^{2}}$, were calculated in the interval of $0.4 \lesssim s \lesssim 5 \mathrm{~nm}^{-1}$ for the $\mathrm{Zn}$ and $0.2 \lesssim s \lesssim 6 \mathrm{~nm}^{-1}$ for the $\mathrm{Mg}$ phosphate glasses, respectively, from the second moment of the particle scattering curves, $I_{\mathrm{P}}(s)$, as given by (7). The uncertainties in $(\Delta \rho)^{2}$ were calculated by error propagation applied to (7). Their amount is smaller than $1 \%$.

For a given volume fraction, $w_{\mathrm{P}}$, the number of heterogeneities, $N$, can be estimated from (6). The smaller the difference between $w_{\mathrm{P}}$ and $\left(1-w_{\mathrm{P}}\right)$ the larger the magnitude 


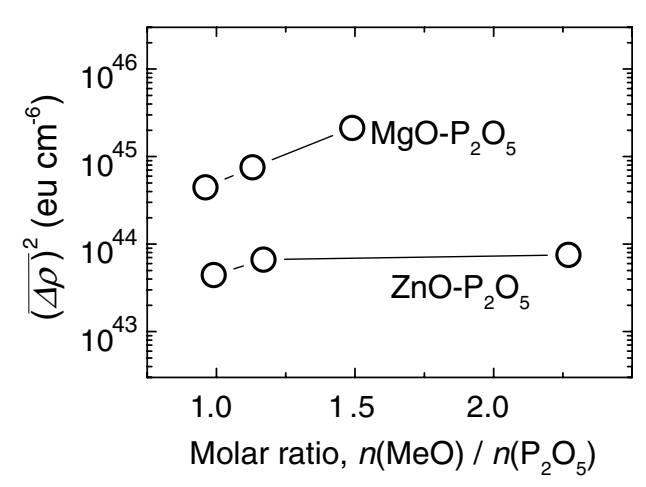

Fig. 6. The mean-square electron density fluctuations, $\overline{(\Delta \rho)^{2}}$, calculated from the scattering curves of the zinc and magnesium phosphate glasses shown in Figs. 3 and 5 after subtracting the scattering of the disordered network as demonstrated in Fig. 1. In the zinc polyphosphate glass with $y=1.81$ small-scale heterogeneities do not exist. Me stands for the metal ion, i.e., $\mathrm{Me}=\mathrm{Mg}$ or $\mathrm{Zn}$, respectively. The lines are drawn as a guide to the eye. The uncertainties in $\overline{(\Delta \rho)^{2}}$ are within the size of the data symbols (for details see Section 4).

of $\overline{(\Delta \rho)^{2}}$, i.e., the stronger the scattering effect [cf. Eqs. (7) and (8)]. If $w_{\mathrm{P}}=0.5$ is assumed, a maximal value for $N$ can be calculated from (6) without making model assumptions. Thus, $N=0.95 \times 10^{21} \mathrm{~cm}^{-3}$ for the $\mathrm{Mg}$ phosphate glasses and $N=0.12 \times 10^{21} \mathrm{~cm}^{-3}$ for the $\mathrm{Zn}$ phosphate glasses is obtained.

The anomalous small angle X-ray scattering measured for the strontium metaphosphate glass (Table 1) is shown

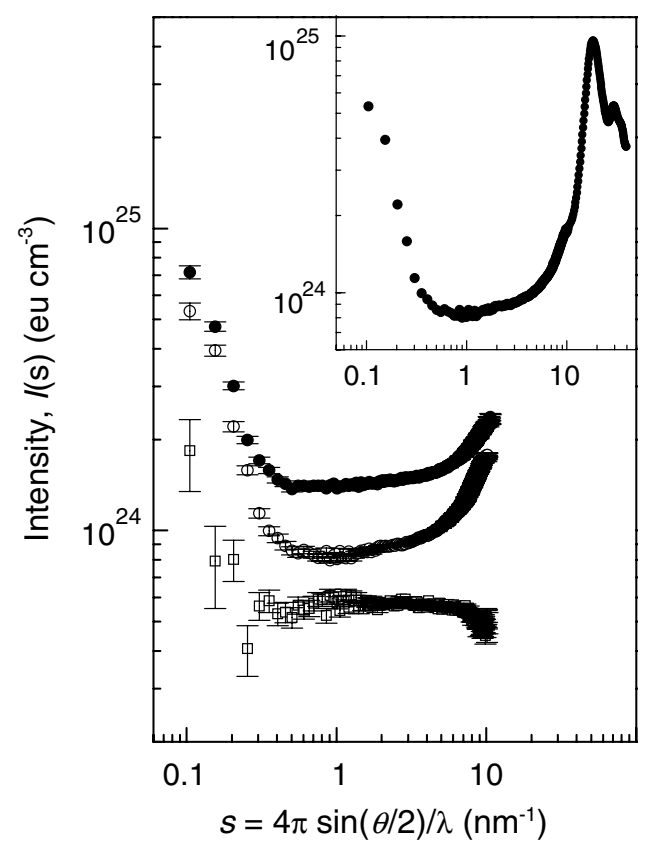

Fig. 7. The anomalous small angle X-ray scattering of the strontium metaphosphate glass sample. The curves were recorded far from the $\mathrm{Sr} K$ absorption edge (open circles, $15610 \mathrm{eV}$ ) and close to the edge (full circles, $16051 \mathrm{eV}$ ). The difference between the two curves is shown by the squares. The uncertainties in $I(s)$ are represented by the error bars. The inset shows the scattering curve measured far from the $\mathrm{Sr} K$-absorption edge once again joined with that obtained with the Rigaku Denki low angle X-ray goniometer. in Fig. 7. In the $s$ range around $10 \mathrm{~nm}^{-1}$ a so-called prepeak $[4,22]$ is observed. For better recognition, the scattering curve measured far from the absorption edge (open circles in Fig. 7) was continued with that obtained with the Rigaku Denki low angle X-ray goniometer and shown in the inset in Fig. 7.

\section{Discussion}

\subsection{Origin of the small angle scattering effect}

A small angle scattering effect appears for all samples investigated with the exception of the aluminium metaphosphate glass (Figs. 1 and 2). The scattering of the latter sample does not show an increase of intensity for decreasing $s$ towards $s=0$ and is caused only by fluctuations in the chemical composition and the topological density. The structure of the aluminium metaphosphate glass was found [18] to be very similar to that of vitreous $\mathrm{SiO}_{2}$. The structure is constituted of chains formed by linked $\mathrm{PO}_{4}$ tetrahedra with $\mathrm{AlO}_{6}$ octahedra incorporated, and the curvature of meandering chains in the aluminium metaphosphate glass is comparable to that of rings in vitreous silica. Consequently, small angle scattering need not be expected to be observed from the aluminium metaphosphate glass. The fact that there is no small angle scattering for the aluminium phosphate glass sample gives evidence that the scattering effects observed for all other glasses are not artifacts due to the surface of the samples as a result of the preparation process. As mentioned above, slab-shaped samples polished on both sides were prepared from each glass exactly using the same procedures.

It was found that samples melted in different crucibles (silica, aluminium, platinum) as well as those where the melting temperature and the melting time were varied yielded the same scattering effects [4]. By varying the crucible material used for preparing zinc polyphosphate glasses, i.e., amorphous carbon instead of silica, while the melting conditions were kept constant, it was found [7] that the small angle scattering effects detected are not associated with the residual silica analyzed in these glasses.

It has been shown $[4,7,20]$ that there are not any crystalline peaks in the concerning intensity functions measured for magnesium and zinc phosphate glasses in the interval of $s$ values between 0.3 and $38 \mathrm{~nm}^{-1}$. Thus it can be excluded that the occurring small angle X-ray scattering originates from crystalline regions in the samples.

The small angle scattering recorded from the samples indicates the presence of two differently-sized heterogeneity regions of electron density.

\subsection{Small-scale heterogeneities in magnesium and zinc phosphate glasses}

The weak small angle scattering in the range around $1 \mathrm{~nm}^{-1}$ is observed only in the curves of the magnesium and zinc phosphate glasses. Also in previous investigations 
$[4,19,22]$ this scattering effect was not found for other binary phosphate glasses containing cations like $\mathrm{Li}, \mathrm{K}, \mathrm{Ag}$, $\mathrm{Co}, \mathrm{Cu}, \mathrm{Cd}, \mathrm{Ba}, \mathrm{Pb}$, and $\mathrm{La}$. The weak scattering detected in the curves for the magnesium and zinc phosphate glasses is an evidence for the existence of small heterogeneities of electron density. Their size is about $1 \mathrm{~nm}$ diameter for the magnesium and about $2 \mathrm{~nm}$ for the zinc phosphate glasses.

Considerable effort has been made to understand the structural background of the heterogeneities established. Previous investigations on magnesium phosphate glass [4] have shown that the observed heterogeneities do not result from liquid-liquid phase separation and we concluded that they are already present in the glass melt. Moreover, it was found [4] that in the magnesium metaphosphate glass the heterogeneities do not act as nuclei for a bulk crystallization.

As can be seen from Fig. 5, the scattering of the $\mathrm{MgO}$ $\mathrm{P}_{2} \mathrm{O}_{5}$ glass sample with $y=0.87$ does not show an increase of intensity as $s \rightarrow 0$ and is caused only by frozen-in fluctuations of electron density. These facts hold true for magnesium ultraphosphate glasses with $y<0.87$ up to vitreous $\mathrm{P}_{2} \mathrm{O}_{5}$ as well [22]. In this range, the fraction of $\mathrm{Q}^{3}$ structural groups linearly increases from zero for $y=1$, i.e., metaphosphate composition, to $100 \%$ for $\mathrm{P}_{2} \mathrm{O}_{5}$ according to van Wazer's reorganization theory [23]. It becomes evident that with formation of an increasing cross-linked network containing more than about $13 \% \mathrm{Q}^{3}$ units the structure becomes more homogeneous. But for the glasses around metaphosphate composition and for all glasses up to $y=1.87$ a weak small angle scattering was recorded [6]. (Fig. 5 presents curves only for those samples of the $\mathrm{MgO}-\mathrm{P}_{2} \mathrm{O}_{5}$ glasses for which the scattering was measured with the Rigaku Denki low angle X-ray goniometer as well as at the ASAXS-Beamline Jusifa). Fig. 6 shows that the mean-square electron density fluctuations increase with increasing $\mathrm{MgO}$ content. The size of the heterogeneity regions does not alter and consequently their number should increase provided that the contrast, $\Delta \rho$, between the particle and the matrix phase remains constant [cf. (6) and (7)]. The scattering curves of these samples (Fig. 5) reveal a maximum in the range of $\sim 2 \mathrm{~nm}^{-1}$. This maximum is caused by interparticle interference, $I_{\mathrm{F}}(s)$ in (1), generated by the heterogeneities of $\sim 1 \mathrm{~nm}$ size. Obviously, the heterogeneity regions formed in the melt possess a certain degree of order attributable to their large number. This structure is frozen-in while cooling down the melt and leads to a distinct correlation maximum in the small angle scattering curves that becomes more pronounced with increasing number of heterogeneities.

Also in the zinc polyphosphate glasses small-scale heterogeneities are present from metaphosphate composition up to that beyond pyrophosphate stoichiometry $(y=2)$. Surprisingly, in the glass with $y=1.81$ there are no small-scale heterogeneities as can be seen from Fig. 4. The meansquare electron density fluctuations, $\overline{(\Delta \rho)^{2}}$, in the Zn phosphate glasses are about one order of magnitude smaller than in the Mg phosphate glasses (Fig. 6). As interference maxima are not observed in the scattering curves for the $\mathrm{Zn}$ phosphate glasses the volume fraction of the heterogeneities can be assumed to be smaller than that in the $\mathrm{Mg}$ polyphosphate glasses. The mean-square electron density fluctuations, $\overline{(\Delta \rho)^{2}}$, exhibit only minor changes with varying $\mathrm{ZnO}$ composition. Therefore, the number of heterogeneities should remain almost constant because the size of the heterogeneities is unchanged.

To get an idea of the heterogeneities existing in the $\mathrm{Mg}$ and $\mathrm{Zn}$ polyphosphate concentration range some results obtained in previous studies $[6,7,24]$ by wide angle diffraction and ${ }^{31} \mathrm{P}$ MAS-NMR are worth considering. The $\mathrm{Zn}^{2+}$ and the $\mathrm{Mg}^{2+}$ ions possess highest electric field strength $\left(0.52 \times 10^{20} \mathrm{~m}^{-2}\right.$ for $\mathrm{Zn}^{2+}, 0.53 \times 10^{20} \mathrm{~m}^{-2}$ for $\left.\mathrm{Mg}^{2+}[25]\right)$ among the mono and divalent modifier ions under discussion. For this reason, the $\mathrm{Q}^{1}$ sites may disproportionate to $\mathrm{Q}^{2}$ and $\mathrm{Q}^{0}$ below pyrophosphate composition $(y=2)$. In the $\mathrm{Mg}$ phosphate glasses, only $\mathrm{Q}^{2}$ units are present at metaphosphate composition $(y=1)$, for the sample with $y=1.13, \mathrm{Q}^{2}$ and $\mathrm{Q}^{1}$ groups exist and for $y=1.49, \mathrm{Q}^{2}$ $(49 \%), \mathrm{Q}^{1}(48 \%)$ and a small fraction of $\mathrm{Q}^{0}$ groups $(3 \%)$ were established. With this progressive depolymerization the number of the heterogeneity regions increases in the $\mathrm{Mg}$ phosphate glasses while their size does not change. For the $\mathrm{Zn}$ polyphosphate glass samples an adequate $\mathrm{Q}^{n}$ distribution was determined. But in these samples the increasing complexity of the melt has no influence on the size and number of the heterogeneity regions. It is not understood that in the glass with composition close to pyrophosphate $(y=1.81)$ the heterogeneities do not exist. This phenomenon was also observed [26] for a series of invert glasses of the system $\mathrm{CaO}-\mathrm{Na}_{2} \mathrm{O}-\mathrm{MgO}-\mathrm{P}_{2} \mathrm{O}_{5}$ $(1.51 \leqslant y \leqslant 2.41)$, i.e., heterogeneity regions between 0.8 and $1 \mathrm{~nm}$ size were established to be present in all glass samples with the exception of that with molar ratio $y=1.99$. But for the $\mathrm{Zn}$ phosphate glasses another phenomenon that a minimum occurs in the compositiondependence of the glass transition temperature, $T_{\mathrm{g}}$, in the range of $y \sim 1.5$ [7] cannot be explained as well.

Structural specifics of these glass systems became also evident in the coordination environment of the modifying cations. Small $\mathrm{Me}-\mathrm{O}$ coordination numbers, i.e., 4 for $\mathrm{Zn}$ and a mixture of 4-, 5- and 6-coordinated $\mathrm{Mg}$ sites, were determined $[6,24]$. But it was found that the $\mathrm{Me}-\mathrm{O}$ coordination sphere does not significantly change across the entire polyphosphate concentration range. Around metaphosphate composition all $\mathrm{O}_{\mathrm{NB}}$ atoms can form bridges, which leads to lowest coordination numbers and thus isolated $\mathrm{MeO}_{n}$ polyhedra are present. With further $\mathrm{MeO}$ incorporation an increasing fraction of oxygens is coordinated by two or more Me sites which results in a strong densification of the glass structure. This coordination behavior determines the composition-dependence of packing density in both glasses systems [6,7], i.e., it is minimal at metaphosphate composition and continuously increases in 
the range of higher $\mathrm{MeO}$ content, but a correlation with the existence of the heterogeneities does not become obvious.

Summarizing this structural knowledge it may be assumed that the small-sized metal-oxygen groups formed by the $\mathrm{Mg}^{2+}$ and $\mathrm{Zn}^{2+}$ ions with their remarkably high electric field strength are the basis for the constitution of heterogeneities of electron density in the melt. As shown below, the anomalous small angle scattering suggests that the $\mathrm{Zn}$ atoms are homogeneously distributed in the regions of small-scale heterogeneities surrounded by the glass matrix. Differences between the heterogeneity regions in the $\mathrm{Mg}$ and $\mathrm{Zn}$ polyphosphate glasses concerning size, volume fraction and its composition-dependence (Fig. 6) may attributable to different structural effects of the $\mathrm{Mg}^{2+}$ and $\mathrm{Zn}^{2+}$ ions. With the $\mathrm{ZnO}_{4}$ groups, silica-like networks are formed in the zinc metaphosphate glasses [24]. The coordination number, $N_{\mathrm{ZnO}}$, is 4 in the metaphosphate glass and in the $\beta-\mathrm{Zn}\left(\mathrm{PO}_{3}\right)_{2}$ crystal, and $N_{\mathrm{ZnO}}=4.1$ was found for a glass with $y=1.86$ while in the $\gamma-\mathrm{Zn}_{2} \mathrm{P}_{2} \mathrm{O}_{7}$ crystal $N_{\mathrm{ZnO}}$ is 5 . For this reason, the differences in the packing density of the glass compared with that of the related crystal are relatively small [7]. On the other hand, there are distinct differences between the coordination number, $N_{\mathrm{MgO}}$, in the glasses $\left(N_{\mathrm{MgO}}=5.3\right.$ for $y=1.13, N_{\mathrm{MgO}}=5.6$ for $y=1.87$, resulting from a mixture of 4-, 5- and 6-coordinated $\mathrm{Mg}$ sites) and the crystals ( 6 in both $\mathrm{Mg}_{2} \mathrm{P}_{4} \mathrm{O}_{12}$ and $\beta-\mathrm{Mg}_{2} \mathrm{P}_{2} \mathrm{O}_{7}$ ). Thus, the differences between the packing density of the glasses and that of the related crystals are greater [6].

It is reasonable to think that clusters consisting of cyclic metaphosphate ions produce the small angle scattering detected. In Mg phosphate glasses, the existence of these rings was assumed [27] to explain the so-called phosphate anomaly [28]. There have been NMR [29] and liquid chromatography studies [30] that provide evidence for small quantities of ring structures in different phosphate glasses. However, Figs. 3 and 5 show that the scattering effect appears across a widely extended polyphosphate range, i.e., even in that range where the fraction of $\mathrm{Q}^{2}$ sites, the presence of which is necessary to form rings, is very small or equal to zero $[6,7,30]$, respectively.

In Ref. [5] it is suspected that compact clusters formed by orthophosphate groups, $\mathrm{Q}^{0}$, are the basis for heterogeneities of $0.8-1 \mathrm{~nm}$ diameter found in a zinc polyphosphate glass with $y=2.1$. But, from Fig. 3 it becomes obvious that the small angle scattering effect is observed for compositions at which there are no $Q^{0}$ units. $\left(Q^{0}\right.$ units were not established in zinc polyphosphate glasses for $y<1.53$ by ${ }^{31}$ P MAS-NMR [7].)

From these facts it may be concluded that the heterogeneities are not identical with clusters formed by arrangements of ring structures or any polyphosphate ions differing in electron density from the surrounding matrix.

\subsection{Large-scale heterogeneities}

Surprisingly, a pronounced small angle X-ray scattering effect indicating the presence of large-scale heterogeneities was detected (Figs. 2, 3 and 5) when we extended the measuring interval to appreciably smaller $s$ values using the ASAXS-Beamline Jusifa at Hamburg Synchrotron Radiation Laboratory.

Unfortunately, the dimension of these heterogeneities cannot be reliably determined from the measured intensities. For the zinc metaphosphate glass, $R=29 \mathrm{~nm}$ was obtained from the first measuring points (cf. the inset in Fig. 4). But for heterogeneities of this size condition (5) requires a Guinier region with largest $s$ value of $1.26 / 29 \mathrm{~nm} \sim 0.043 \mathrm{~nm}$, which is significantly smaller than the smallest measured $s$ value of $s_{\min }=0.055 \mathrm{~nm}^{-1}$. (Deviations from the spherical shape lead even to a shortening of the Guinier region, i.e., the constant in (5) becomes considerably smaller than 1.26.) Because of the deviations from the Guinier approximation (3), the dimension determined is appreciably too large. From a Guinier plot of the large-scale heterogeneities in the magnesium metaphosphate glass $(y=0.96)$ the size was obtained to be $R=10.5 \mathrm{~nm}$, which seems to be more realistic. In this case, $s_{\min }=0.105 \mathrm{~nm}^{-1}$ is somewhat smaller than $1.26 / 10.5 \mathrm{~nm}=0.12 \mathrm{~nm}$. For determining reliable dimensions for the large-scale heterogeneities the measurements must be extended to smaller $s$ values.

There is no fundamental knowledge on the nature of large-scale heterogeneities found in phosphate glasses. The binary phosphate glasses studied are known to be rather hygroscopic. The large-scale heterogeneities might suspected coming from water contamination. This hypothesis is supported by the observation that the small angle scattering effect is detected for all samples studied with the exception of the aluminium phosphate glass. The latter glass with its silica-like structure exhibits reactivity with moisture comparable to that of vitreous $\mathrm{SiO}_{2}$. Moreover, Fig. 5 suggests that the small angle scattering effect measured from $\mathrm{MgO}-\mathrm{P}_{2} \mathrm{O}_{5}$ glasses is more pronounced when the age of the sample increases. Whether differences of electron density inherent in the surface of the sample or in the bulk material give rise to the small angle scattering cannot be distinguished.

${ }^{1} \mathrm{H}$ NMR MAS studies [31] have established that in crystalline water containing calcium phosphates hydrogen atoms may occur in the form of hydroxyl groups, $\mathrm{HPO}_{4}^{2-}$ groups, and $\mathrm{H}_{2} \mathrm{O}$ groups, and each of these may be either structural or surface absorbed. The water protons were found to possess a substantial isotropic mobility. In contrast to these polyphosphate structures, such $\mathrm{H}-\mathrm{H}$ pair distances as typical of water molecules or clusters of hydrogen bridges could not be detected [32] in vitreous ultraphosphate structures. The network-modifying effect in these structures mainly consists in breaking $\mathrm{P}-\mathrm{O}-\mathrm{P}$ bridges with $\mathrm{H}^{+}$ions forming $\mathrm{O}-\mathrm{H} \cdots \mathrm{O}$ bridges connecting two corners of adjacent $\mathrm{PO}_{4}$ units. Perhaps, further experiments with specifically prepared samples and, because of their different contrasts in relation to X-rays, small angle scattering experiments with neutrons may give additional information on correlations of the heterogeneities with effects of water in the glasses. 
5.4. Anomalous small angle scattering of zinc and strontium phosphate glass

For the series of samples presented in this study, the facilities at ASAXS-Beamline Jusifa permitted the anomalous small angle scattering to be studied for the zinc and strontium phosphate glasses. When recorded close to the $\mathrm{Zn}$ or $\mathrm{Sr} K$-absorption edge, respectively, the scattered intensities were observed to alter in relation to those recorded far from the edge across the entire $s$ range measured (Figs. 3 and 7). But for the $\mathrm{Sr}$ and the $\mathrm{Zn}$ phosphate glass with $y=1.81$, respectively, small-scale heterogeneities are not present in the glasses. In the scattering curves of these samples, the increase of intensity for $s \gtrsim 0.4 \mathrm{~nm}^{-1}$ must have caused by other scattering effects. As the energy was chosen such that fluorescence was avoided, the additional scattering observed can be expected to be produced by resonant X-ray Raman scattering [33]. The intensity of this scattering effect, which may occur for energies smaller than that of the absorption edge, depends on the atoms contained in the sample, but it is independent on the scattering angle. The magnitude of the resonant Raman scattering is represented for the $\mathrm{Zn}$ phosphate glasses by the difference between the two scattering curves with $y=1.81$ for $s \gtrsim 0.4 \mathrm{~nm}^{-1}$ (Fig. 3). Within the uncertainties, this difference agrees with the concerning differences determined for the $\mathrm{Zn}$ phosphate glasses containing small-scale heterogeneities $(y=0.99,1.17,2.27)$. Evidently, for each glass the changes of intensity produced by the small-scale heterogeneities exclusively originate from resonant Raman scattering effects. Consequently, the $\mathrm{Zn}$ atoms are homogeneously distributed in the two phases formed by the smallscale heterogeneities and the glass matrix.

The well pronounced scattering of the large-scale heterogeneities is not significantly influenced by the resonant Raman scattering. The increase of intensity for energies close to the absorption edge shows that the $\mathrm{Zn}$ or $\mathrm{Sr}$ atoms, respectively, are not homogeneously distributed in the regions of large-scale heterogeneities surrounded by the glass matrix. The dimensions of the heterogeneities determined from the difference curves, i.e., the difference between the intensities measured far from and close to the absorption edge demonstrated in Fig. 7, did not change. As the intensity, $I(s, E)$, is proportional to the contrast, $\Delta \rho$, [cf. Eq. (8)], the increase of $I(s, E)$ requires an increase of the effective contrast. Consequently, the zinc or strontium atoms, respectively, must be higher concentrated in the phase that has lower electron density. Whether the electron density is lower within the heterogeneities or within the matrix cannot be distinguished by the diffraction experiment.

It should be mentioned that a so-called prepeak is observed for the strontium metaphosphate glass in the $s$ range around $10 \mathrm{~nm}^{-1}$. Fig. 7 shows that the intensities measured close to the absorption edge decrease in the range of the prepeak. Thus, the species responsible for the constitution of the prepeak should have correlations with the $\mathrm{Sr}$ atoms. Here, a more detailed interpretation of this effect is hardly possible. The prepeak is known $[4,22]$ to origin from the intermediate range structure. In the strontium metaphosphate glass, the structure is dominated by alternating sequences of arrangements of phosphate chains and conglomerates of $\mathrm{SrO}_{n}$ polyhedra. The length scale of these sequences correlates with the distances of the P-P pairs $(\cong 0.7 \mathrm{~nm})$. As extracted from diffraction experiments by using reverse Monte Carlo simulations [3,34] these distances dominantly contributes to the formation of the prepeak, but there are also some contributions of $\mathrm{Sr}-\mathrm{Sr}$ distances to this peak.

\section{Summary}

A small angle scattering effect was detected for all samples investigated with the exception of the aluminium metaphosphate glass. The small angle scattering recorded indicates the presence of two differently-sized heterogeneity regions of electron density. The scattering effects observed were shown neither to be artifacts attributable to the preparation process nor originate from crystalline regions in the glasses.

The small-scale heterogeneities are present in magnesium and zinc phosphate glasses only. The species do not result from liquid-liquid phase separation and do not act as nuclei for a bulk crystallization. Their size is about $1 \mathrm{~nm}$ diameter in the magnesium and about $2 \mathrm{~nm}$ in the zinc phosphate glasses. It must be assumed that the small-scale heterogeneities are a result of the frozen-in structure of the heterogeneous glass melt. It was found that they are not identical with any kind of clusters formed by arrangements of ring structures or any polyphosphate ions.

There is no fundamental knowledge on the nature of the large-scale heterogeneities. The small angle scattering suggests that their occurrence is related to water contamination.

Anomalous small angle X-ray scattering experiments have shown that the $\mathrm{Zn}$ atoms are homogeneously distributed in the two phases formed by the small-scale heterogeneities and the glass matrix. But in the regions of large-scale heterogeneities surrounded by the glass matrix the $\mathrm{Zn}$ or $\mathrm{Sr}$ atoms, respectively, are not homogeneously distributed. These atoms are higher concentrated in the phase that has lower electron density.

\section{References}

[1] Y. Abe, H. Hosono, in: T. Kanazawa (Ed.), Inorganic phosphate materials, Materials Science Monographs, vol. 52, Kodansha, Elsevier, Tokyo, Amsterdam, 1989, p. 247.

[2] R.K. Brow, J. Non-Cryst. Solids 263\&264 (2000) 1.

[3] U. Hoppe, G. Walter, R. Kranold, D. Stachel, J. Non-Cryst. Solids 263\&264 (2000) 29 .

[4] G. Walter, R. Kranold, D. Stachel, W. Götz, Phys. Chem. Glasses 31 (1990) 188.

[5] A.B. Baranov, B.B. Golubkov, B.I. Petrov, Fiz. Khim. Stekla 25 (1999) 385. 
[6] G. Walter, J. Vogel, U. Hoppe, P. Hartmann, J. Non-Cryst. Solids 320 (2003) 210.

[7] G. Walter, U. Hoppe, J. Vogel, G. Carl, P. Hartmann, J. Non-Cryst. Solids 333 (2004) 252.

[8] A.C. Wright, J.L. Shaw, S.J. Clarke, R. Haworth, R.N. Sinclair, XX International Congress on Glass, September 27-October 1, 2004, Kyoto, Japan, Abstracts, p. 177.

[9] K. Müller, in: O. Glatter, O. Kratky (Eds.), Small-Angle X-ray Scattering, Academic, New York, 1982, p. 230.

[10] G. Walter, P.W. Schmidt, J. Appl. Crystallogr. 14 (1981) 28.

[11] G. Walter, R. Kranold, W. Göcke, N. Enenkel, J. Appl. Crystallogr. 24 (1991) 616

[12] O.V. Mazurin, E.A. Porai-Koshits, Phase Separation in Glass, NorthHolland Physics Publishing, Amsterdam, 1984.

[13] G. Walter, R. Kranold, D. Enke, G. Goerigk, J. Appl. Crystallogr. 36 (2003) 592.

[14] A. Guinier, G. Fournet, Small-Angle Scattering of X-rays, Wiley, New York, 1955.

[15] V. Gerold, Z. Angew. Phys. 9 (1957) 43.

[16] G. Porod, in: O. Glatter, O. Kratky (Eds.), Small-Angle X-ray Scattering, Academic, New York, London, 1982, p. 17.

[17] L.A. Feigin, D.I. Svergun, in: G.W. Taylor (Ed.), Structure Analysis by Small-Angle X-Ray and Neutron Scattering, Plenum, New York, 1987, p. 143.

[18] U. Hoppe, G. Walter, D. Stachel, A.C. Hannon, Z. Naturforsch. a 50 (1995) 684

[19] R. Kranold, G. Walter, U. Lembke, Th. Rieker, D. Stachel, J. NonCryst. Solids 232-234 (1998) 502.
[20] G. Walter, U. Hoppe, R. Kranold, D. Stachel, Phys. Chem. Glasses 35 (1994) 245.

[21] T. Gerber, G. Walter, P.W. Schmidt, J. Appl. Crystallogr. 24 (1991) 278.

[22] G. Walter, U. Hoppe, T. Baade, R. Kranold, D. Stachel, J. NonCryst. Solids 217 (1997) 299.

[23] J.R. van Wazer, Phosphorus and Its Compounds, vol. 1, Interscience, New York, 1958.

[24] U. Hoppe, G. Walter, G. Carl, J. Neuefeind, A.C. Hannon, J. NonCryst. Solids 351 (2005) 1020.

[25] G.E. Brown Jr., F. Farges, G. Calas, in: J.F. Stebbins, P.F. McMillan, D.B. Dingwell (Eds.), Structure, dynamics and properties of silicate melts, Reviews in Mineralogy, vol. 32, Mineralogical Society of America, Washington, DC, 1995, pp. 322-323.

[26] G. Walter, J. Vogel, U. Hoppe, P. Hartmann, J. Non-Cryst. Solids 296 (2001) 212.

[27] T. Kanazawa, J. Non-Cryst. Solids 52 (1982) 187.

[28] E. Kordes, W. Vogel, R. Feterowsky, Z. Elektrochem. 57 (1953) 282.

[29] F. Fayon, D. Massiot, K. Suzuya, D.L. Price, J. Non-Cryst. Solids 283 (2001) 88.

[30] B.C. Sales, L.A. Boatner, J.O. Ramey, J. Non-Cryst. Solids 263\&264 (2000) 155

[31] J.P. Yesinowski, H. Eckert, J. Am. Chem. Soc. 21 (1987) 6274.

[32] U. Hoppe, R. Kranold, D. Stachel, A. Barz, C.J. Benmore, Z. Naturforsch. a 59 (2004) 879.

[33] C.J. Sparks Jr., Phys. Rev. Lett. 33 (1974) 262.

[34] U. Hoppe, R. Kranold, A. Barz, D. Stachel, J. Neuefeind, D.A. Keen, J. Non-Cryst. Solids 293-295 (2001) 158. 